\title{
The situational cognitive mediation effects on dispositional personality influence on the intention to use the internet: an empirical study of information technology acceptance within higher education institution
}

\author{
Willy Abdillah \\ Faculty of Economics, \\ University of Bengkulu, \\ Jl. Raya Kandang Limun, \\ Kota Bengkulu 38223, Indonesia \\ Fax: (0274) 524606 \\ Email: aufa_fairuz2000@yahoo.com

\begin{abstract}
The objective of this research is to investigate the effect of dispositional personality factors on intention to use internet which mediated by situational cognitive factors. Personality factors are measured by five variables which are openness to experience, conscientiousness, extraversion, agreeableness and neuroticism. Then, situational cognitive factors are measured by perceived ease of use, perceived usefulness and self-efficacy. Survey was conducted on 350 students of Faculty of Economics, University of Bengkulu. Hypotheses testing conducted using Partial Least Square (PLS) with software SmartPLS version 2.0. Result shows that only openness to experience and extraversion from personality factors is significantly affected on situational cognitive factors. Meanwhile, perceived usefulness and self-efficacy are positively affected from situational cognitive factors on intention to use internet. It is indicated that situational cognitive factors were significantly mediated relationship between dispositional personality factors towards intention to use internet.
\end{abstract}

Keywords: dispositional personality; situational cognitive; IT acceptance; information technology acceptance; IS; information system.

Reference to this paper should be made as follows: Abdillah, W. (2009) 'The situational cognitive mediation effects on dispositional personality influence on the intention to use the internet: an empirical study of information technology acceptance within higher education institution', Int. J. Management in Education, Vol. 3, Nos. 3/4, pp.359-374.

Biographical notes: Willy Abdillah is a Lecturer in Management at the Faculty of Economics, University of Bengkulu, Indonesia, and Master of the Science Program, Faculty of Economics and Business, Gadjah Mada University, Indonesia. 


\section{Introduction}

In the development of the behavioural Information System (IS) research, the perceptual cognitive constructs have been dominantly used and well-built in enlightening the acceptability phenomenon as well as the adoption of Information Technology (IT), such as on the Theory of Reason Action (TRA), the Theory of Acceptance Model (TAM), the Theory of Planned Behaviour (TPB) and the Unified Theory of Acceptance and Usage of Technology (UTAUT). On the contrary, the use of personality constructs is not yet done compactly, and they are dominantly situational such as the internet anxiety construct and personal innovativeness (Thatcher et al., 2007). Furthermore, the discussion on the relationship between the dispositional personality factors and the situational is still inconclusive. The first perspective regarded that personality is a dispositional factor which is unmodifiable (Amiel and Sargent, 2004; Landers and Lounsbury, 2006). Personality is defined as individual identities that describe the thinking pattern, emotion and actions which differentiate him from the others (Maddi, 1989 in McElroy et al., 2007). Therefore, the personality factor is valued as somewhat unalterable by the situational factors and the condition on where the person is sited. However, some of the behavioural IS researches have shown that the application of the dispositional personality factors is inaccessible on the IS context which is very situational.

What is more is that, a few researches earlier revealed that there is an inconsistency concept and distant discoveries. Thatcher et al. (2007) encountered that the internet anxiety inspire the personality trait. On the other hand, Agarwal and Karahanna (2000) discovered the personality trait (the openness to experience which extracted to be the personal innovativeness) is influencing the accessibility of employing the perception and the appliance of the perception (situational cognitive).

Based on lag being in theory as well as empirical which is exposed by the discussion on the influence of the dispositional factors (personality trait and cognitive style), and the situational factors (the personality perception and the cognitive perception), therefore by replicating and developing McElroy et al. (2007) and Buchanan et al. (2005) research model, this study is aimed to describe the influence of dispositional personality factors (personality trait) and the situational cognitive factors (cognitive perception) towards the intention to use the internet based on the empirical studies at institution of higher education's medium.

Systematically, this paper is divided into four sections; the first section is explaining the theoretical background and the dispositional personality concept, as well as the situational cognitive. The second section is describing the research method applied in this research. The third section is clarifying the result and founding. And the last section is the conclusion and the recommendation for further research.

\section{Theoretical background}

\subsection{Dispositional personality}

Researches in the field of IS which use the personality concept was commenced by Zmud (1979) who considered the individual dispositional characteristics (personality and cognitive style) towards the success in implementing the IS. Personality factors were measured from the point of cognitive structure and also in terms of an individual which 
is affective in responding events, people and the situation on where he encountered. The personality factors which are determined to have a strong influence towards the success of the Management of Information System (MIS) are the locus of control, dogmatism, ambiguity of tolerance, extrovert or introvert, the need towards achievements, the dauntless in taking risk, the evaluative resistance and the level of anxiety (Klauss and Jewett, 1974 in Zmud, 1979). The result showed that the dispositional factors (the personality trait and the cognitive style) are really affecting the favourableness of using IT. Nonetheless, the researches at that era still have not yet discover the personality dimension which is consistent since they still employ the dimensions and variables from the studies beyond of the MIS, and those personality dimensions were unrelated to the cognitive style factors.

The employment of the five dimensions of the Big Five Factor Personality within the behaviour to use the internet has actually been exercised previously by few researchers. Yi et al. (2006) stated that the prime mainstream in the IS adoption research pointed the individual characteristics and the personality to be the predictor for cognitive factor as like the perceived ease of use and the perceived usefulness. Specifically, some of the results revealed that the agreeableness is a predictor of using internet but likely not to interact to computer for long time, and the behaviour to use the internet especially when they experienced a frustration (Landers and Lounsbury, 2006). Therefore, this character is suspected to also construct the perceived usefulness and the self-efficacy of the IT user.

Based on the statements above, therefore, the hypotheses constructed for this study are as follows:

Hypothesis 1a: The 'agreeableness' factor influenced the 'perceived usefulness' in using the internet.

Hypothesis 1b: The 'agreeableness' factor influenced the 'self-efficacy' in using the internet.

Venkantesh (2000) stated that individual characters factor and personality are the antecedent of the cognitive factor (perceived ease of use, perceived usefulness and self-efficacy) in predicting the intention and the behaviour of the IT user. The conscientiousness character tends not to use the internet towards matters that are reputed to be unproductive such as the chatting room; and will liable to use the internet on certain needs which are assumed as productive such as the in quest of articles and academic journals (Landers and Lounsbury, 2006).

Based on the details above, therefore, the hypotheses constructed for this study are as follows:

Hypothesis 2a: The 'conscientiousness' factor influenced the 'perceived usefulness' in using the internet.

Hypothesis 2b: The 'conscientiousness' factor influenced the 'self-efficacy' in using the internet.

The extraversion tends to use the internet for an online needs of socialisation such as the chatting room and the sharing of information with the cyber community (Amiel and Sargent, 2004) and also to percept the benefit of the internet as a facility to have fun and enjoyment. Therefore, this character has a self-efficacy to use the internet for social concern and pleasure (Venkantesh, 2000). 
Based on the explanation above, therefore, the hypotheses constructed for this study are as follows:

Hypothesis 3a: The 'extraversion' factor influenced the 'perceived usefulness' in using the internet.

Hypothesis 3b: The 'extraversion' factor influenced the 'self-efficacy' in using the internet.

The neuroticism tends to evade the internet for the needs of socialisation, but to use them for the needs of private amusement (online game) and to search for one self-identity in the cyber world (Amiel and Sargent, 2004).

Venkantesh (2000) confirmed that perception on usefulness and the self-efficacy to use IT is formed by the fright perception or anxiousness. It means that, a person which has a petrified character may influence the perceived usefulness and his self-confidence towards the kind of IT he exercise.

Based on the details above, therefore, the hypotheses constructed for this study are as follows:

Hypothesis 4a: The 'neuroticism' factor influenced the 'perceived usefulness' in using the internet.

Hypothesis 4b: The 'neuroticism' factor influenced the 'self-efficacy' in using the internet.

The openness to experience tends to perform activities in the cyber world just to get in a quest for new ideas (Tuten and Bosnjak, 2001). This character tends to have high desire to explore IT, has a positive perception towards IT, and self-confidence in using IT (Venkantesh, 2000).

Based on the explanation above, therefore, the hypotheses constructed in this study are as follows:

Hypothesis 5a: The 'openness to experience' factor influenced the 'perceived usefulness' in using the internet.

Hypothesis 5b: The 'openness to experience' factor influenced the 'self-efficacy' in using the internet.

\subsection{Situational cognitive}

The development of cognitive concept in IS is established when the mainstream of behavioural research rise in 1960s. Ackoff (1960) has started with the performing of case studies to explore the reason in the IS failure. The research has stimulated the next study although the result failed to locate the roots on why the system had failed, but it has indicated that there is an attitude relationship and the system user behaviour towards the achieving of the IS.

Davis (1989) developed the TRA model and modified the belief construct with the perceived usefulness construct and the perceived ease of use construct. The TAM model is reputed as more parsimony in describing the behaviour in using IS and also supported by many empirical researches. In spite of this, the TAM model divided the cognitive and the affective aspect with the making of the belief construct as the cognitive aspect and attitude as the affective aspect. 
In this study, the cognitive factors used are taken from the construct in the TAM model (Davis et al., 1989), which is the perceived usefulness, the perceived ease of use and the self-efficacy construct, as stated in Bandura (1982); Compeau and Higgins (1995) and Hsu and Chiu (2004). The preference is based on few accounts which are as follows:

1 The TAM is a behaviour model which could explain the question on why so many failures in application of the IS and this is because of the user has no intention to employ it. There are not many information and technology system application models which count the psychology factor or the behaviour in their model, and for this we can consider the TAM for it.

2 The TAM is based on robust theories.

3 The TAM has been tested in many researches and dominantly they supported and concluded that the TAM is a worth model. Furthermore, the TAM has been often tested and compared with other models such as the TRA and the TPB, and the result is consistent to show that the TAM is a good model.

4 The most important asset of the TAM is that it is parsimony model which made it an unpretentious but valid.

5 Particularly for self-efficacy, it has been used in researches as a cognitive construct in influencing the use of IS.

\subsection{Perceived usefulness}

The perceived usefulness is a believe level of a person where by using certain technology could help him in increasing his performance (Davis, 1989). Prior studies revealed that the perceived usefulness construct is positive and significantly affected the use of IS (Davis, 1989; Igbaria et al., 1997). The perceived usefulness is the most dominantly significant and important in inspiring attitude, interest and behaviour in using technology compared to other constructs (Venkantesh, 2000; Venkantesh, 2003; Chesney, 2006; Kim et al., 2007; Lu et al., 2007).

Based on the explanation above, therefore, the hypothesis presented in this study is as follows:

Hypothesis 6: 'Perceived usefulness' factor positively affects the intention to use the internet.

\subsection{Perceived ease of use}

Davis et al. (1989) defined the perceived ease of use as a determination level of a person where there is no requirement for great attempt to use a certain technology. Although it is assumed that the effort necessitate in each person is different to one another but to avoid the rejection on the system developed, therefore, the IS constructed would have to be simple so that the user would not have to use great effort.

The perceived ease of use is one of the factors in the TAM model which has been tested in the research done by Davis et al. (1989). The result proved that perceived ease of use could explain the reason why a person used an IS and describe how the new IS can be accepted by user (Venkantesh, 2000; Venkantesh, 2003; Ndubisi, 2005; Chesney, 2006; Barnett et al., 2007; Lu et al., 2007). 
Based on the explanation above, therefore, the hypothesis presented in this study is as follows:

Hypothesis 7: 'Perceived ease of use' factor positively influences the intention to use the internet by considering gender and age as the control variables.

Furthermore, Davis et al. (1989), Venkantesh (2003) and Yi et al. (2006) discovered that the perceived ease of use is the perceived usefulness predictor besides giving an undeviating affect to the intention to use the IS.

Based on the details above, therefore, the hypothesis presented in this study is as follows:

Hypothesis 8: The 'perceived ease of use' factor positively influences the 'perceived usefulness' in using the internet.

\subsection{Self-efficacy}

Besides the use of perceived construct, this study also employs the self-efficacy construct which is based on the reason that self-efficacy is a situational cognitive construct that can be modified in certain context. Self-efficacy is defined as a convincing towards the ability in doing certain action and the persistency to counter obstacles in order to achieve a performance through certain behaviour (Hartono, 2007a). Bandura (1982) stated that self-efficacy is an alteration on the aspect of human psychology as a response to different treatments, such as when a person is encountering different task complexities; as a result the self-efficacy will then be different too.

Webster and Martocchio (1992, 1993) have conducted a research about self-efficacy with the use of a five-scaled item that has been developed by Hollenbeck and Brief (1987). This is the instrument which, by then, were frequently used by several post-researches in order to assess the self-efficacy, and one of them was the research conducted by Compeau and Higgins (1995). Most of the results revealed that self-efficacy affected the intention to use the IT, the computer anxiety (Agarwal and Karahanna, 2000), the adoption of a highly sophisticated products (Hill et al., 1987) and the intention to make innovations (Burkhat and Brass, 1990). Venkantesh (2000) found that selfefficacy is one of adequate predictors of perceived usefulness in using of IT.

Based on the explanation above, therefore, the hypotheses presented in this study are as follows:

Hypothesis 9: The 'self-efficacy' factor positively influences the 'perceived usefulness' in using the internet.

Hypothesis 10: The 'self-efficacy' positively influences the intention to use the internet.

\subsection{The research framework}

The research framework constructed is as shown below (Figure 1). 
Figure 1 The research framework

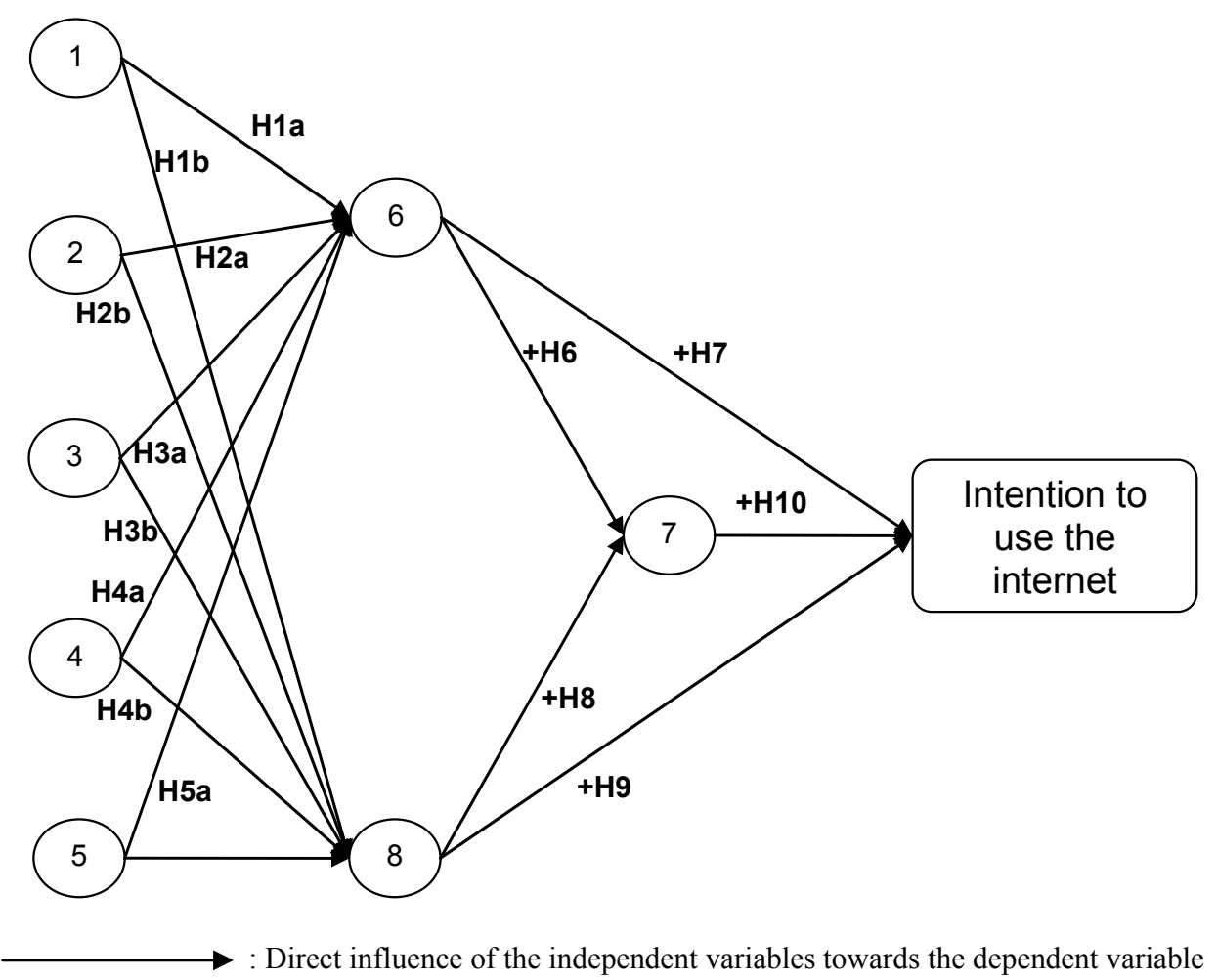

1 Openness to experience

2 Conscientiousness

3 Extraversion

4 Agreeableness

5 Neuroticism

6 Perceived ease of use

7 Perceived usefulness

8 Self-efficacy

Source: Adapted from McElroy et al. (2007); Buchanan et al. (2005); Davis et al.

(1989); Bandura (1982); Compeau and Higgins (1995); Hsu and Chiu (2004)

\section{Research method}

This study adapted a descriptive-confirmatory style which aimed to retest and develop the research model in order to enlighten the causal relationship between variables (the personality, the cognitive factor and the intention to use the internet) by using survey as the tool (Hair et al., 2006).

The perceived usefulness and the perceived ease of use construct are measured by the Likert scale, starting from point ' 1 ' as strongly disagree to point ' 5 ' as strongly agree, which is measured through six questions adopted from Davis et al. (1989). Self-efficacy is 
also assessed with the Likert scale, starting from point ' 1 ' as strongly disagree to point ' 5 ' as strongly agree, which is assessed through five questions adopted from Hsu and Chiu (2004). The dispositional personality is measured by using the Five Factor Personality instrument from the International Personality Item Pool (IPIP), as cited by Goldberg (1990) which consists of five dimensions; the openness to experience, the conscientiousness, the extraversion, the agreeableness and the neuroticism. Each dimension is assessed through the Likert scale starting from point ' 1 ' as strongly disagree, to point ' 5 ' as strongly agree. Whereas the intention to use the internet is measured through the Likert scale starting from point ' 1 ' as strongly disagree to point ' 5 ' as strongly agree by adapting three questions based on Davis et al. (1989).

The population used in this research is the students of Faculty of Economics, University of Bengkulu (FE Unib), which is identified as the internet user including the students of Magister Management and the Extension Program on the total of 350 respondents. We use the non-probability with the purposive-judgement sampling technique as the sample taking procedure. Cross-sectional method is used to collect the data within June 2008 through closed-question structured questionnaires.

The instrument is tested by using the face validity and the content validity, and was conducted by considering the academic view particularly in the field of information and technology system, whereas the validity construct (the convergent and discriminant) and the testing of hypotheses are assessed by using Partial Least Square (PLS) method with software SmartPLS 2.0 application.

\section{Data analysis}

\subsection{Research sample characteristics}

Unit of analysis in this study is the individual or students who are the internet user within the FE Unib. From the 350 distributed questionnaires, only 348 were returned. From those questionnaires, only 323 of them can be processed further because 25 of the questionnaires were incomplete or there were an inclination of them to only fill one choice of scale (central tendency).

The characteristics of those 323 samples can be seen in Table 1 below.

Table 1 Sample characteristics

\begin{tabular}{lccc}
\hline Characteristics & Total & Percentage (\%) & Mean \\
\hline Gender & 135 & 44 & \\
Male & 188 & 56 & \\
Female & & & 20.76 \\
& & & \\
Age & 219 & 67.80 & \\
Less than 20 years & 95 & 29.42 & \\
21-30 years & 9 & 2.78 & \\
More than 30 years & & & \\
\hline
\end{tabular}

Source: Data processed (2008) 
Based on the frequency distribution result, the respondents are dominantly full-grown from bachelor degree category of education. This becomes the basic in determining the personality characteristics and the respondent cognitive at a youth life cycle. While, the distribution of gender showed that the proportion of female is somewhat greater although the distance is not too big. As a consequence, the comparing of influence of gender towards personality, and cognitive towards the intention to use the internet will not potentially hoist bias because of the balance proportion.

The measuring result of the model which is used to test the validity can be seen in Figure 2 below.

Figure 2 The output of the measurement model (see online version for colours)

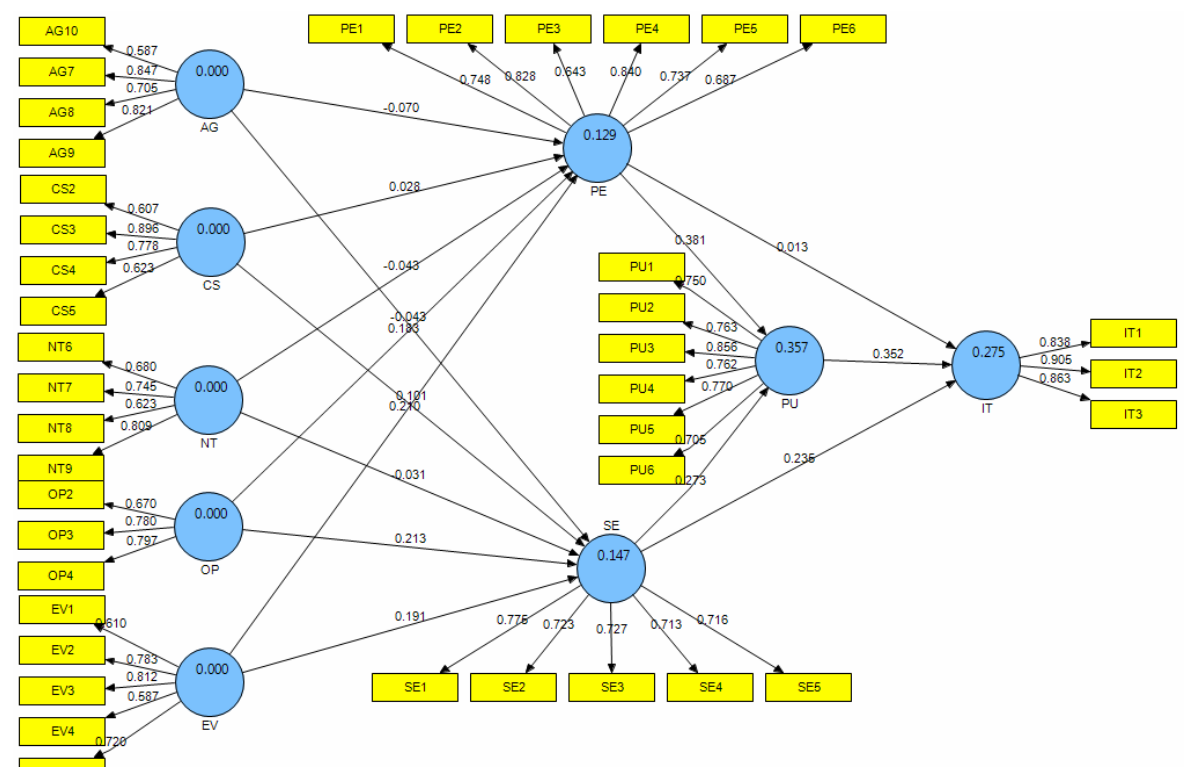

The description of data for validity and reliability testing by using PLS method can be seen in Table 2 below.

Table 2 Output of measurement model

\begin{tabular}{lcccccc}
\hline \multirow{2}{*}{ Constructs } & AVE & $\begin{array}{c}\text { Composite } \\
\text { reliability }\end{array}$ & $R^{2}$ & $\begin{array}{c}\text { Cronbach's } \\
\text { alpha }\end{array}$ & Communality & Redundancy \\
\hline AG & 0.55827 & 0.832173 & & 0.745508 & 0.55827 & \\
CS & 0.540927 & 0.821113 & & 0.730987 & 0.540927 & \\
EV & 0.501409 & 0.831844 & & 0.751625 & 0.501409 & \\
IT & 0.755191 & 0.902392 & 0.275326 & 0.837575 & 0.755191 & 0.007305 \\
NT & 0.515088 & 0.808026 & & 0.700913 & 0.515088 & \\
OP & 0.564183 & 0.794314 & & 0.613311 & 0.564183 & \\
PE & 0.563159 & 0.884619 & 0.128751 & 0.842925 & 0.563159 & 0.006751 \\
PU & 0.591518 & 0.896467 & 0.356992 & 0.860967 & 0.591518 & 0.165599 \\
SE & 0.534409 & 0.851489 & 0.14723 & 0.782189 & 0.534409 & 0.002959 \\
\hline
\end{tabular}


Based on the testing result of the measurement model by using the PLS method, the value of AVE as well as communality is $>0.5$. These findings pointed the research model used has accomplish the construct validity test. Whereas for the reliability test, the model above has performed all reliability requirements such as Cronbach's alpha parameter $>$ 0.6 or reliability composite $>0.7$ (Chin, 1995).

The testing for the Goodness of Fit (GOF) in PLS method is not compulsory. This is because the PLS method is only use as a prediction model, therefore the parameter which is use to see the $G O F$ of the prediction model is the $\mathrm{R}^{2}$. But for certain situation or if needed, a researcher can count himself the GOF as PLS withhold all direct information of GOF. According to Tenenhaus et al. (2005), the formula to calculate GOF is GOF $=\sqrt{ }$ average $\mathrm{R}^{2} \times$ average communality. By using the formula above, the GOF value for this research model is $36 \%$. Based on the finding, it can be concluded generally that the GOF of this research model is $36 \%$.

Based on the $\mathrm{R}^{2}$ output, the independent variables prediction ability towards the dependent variable is only $27 \%$. It means that, the variance of dependent variable which is caused by the variance of the independent variables is only $27 \%$, whereas the $78 \%$ left is confirmed by other variable outside of this research model. Although the $\mathrm{R}^{2}$ value can be used as a parameter to determine the $G O F$ of this prediction model, the $\mathrm{R}^{2}$ is not the major parameter. The key point is how the prediction relation between variables can be finely described by using $\mathrm{T}$ statistic value of significance parameter. below:

The result of the structural model in testing the hypotheses can be seen as in Table 3

Table 3 The coefficient of regression beta, the T-value and the P-value

\begin{tabular}{lccc}
\hline & Original sample & P-value & T-value \\
\hline $\mathrm{AG} \geq \mathrm{PE}$ & -0.050919 & 0.62225 & 0.674444 \\
$\mathrm{AG} \geq \mathrm{SE}$ & 0.077981 & 0.606948 & 0.709998 \\
$\mathrm{CS} \geq \mathrm{PE}$ & 0.024035 & 0.779305 & 0.361256 \\
$\mathrm{CS} \geq \mathrm{SE}$ & 0.069857 & 0.451031 & 1.167017 \\
$\mathrm{EV} \geq \mathrm{PE}$ & 0.218417 & 0.174333 & 3.559998 \\
$\mathrm{EV} \geq \mathrm{SE}$ & 0.176125 & 0.219404 & 2.785787 \\
$\mathrm{NT} \geq \mathrm{PE}$ & -0.065440 & 0.459507 & 1.136048 \\
$\mathrm{NT} \geq \mathrm{SE}$ & -0.024333 & 0.751791 & 0.410921 \\
$\mathrm{OP} \geq \mathrm{PE}$ & 0.194836 & 0.181716 & 3.407711 \\
$\mathrm{OP} \geq \mathrm{SE}$ & 0.223485 & 0.181362 & 3.414737 \\
$\mathrm{PE} \geq \mathrm{IT}$ & 0.013489 & 0.446307 & 0.170301 \\
$\mathrm{PE} \geq \mathrm{PU}$ & 0.379982 & 0.055142 & 5.714671 \\
$\mathrm{PU} \geq \mathrm{IT}$ & 0.351325 & 0.065137 & 4.818362 \\
$\mathrm{SE} \geq \mathrm{IT}$ & 0.235294 & 0.115661 & 2.629888 \\
$\mathrm{SE} \geq \mathrm{PU}$ & 0.274221 & 0.078275 & 3.984251 \\
\hline
\end{tabular}

Source: Statistical survey (2008) 


\section{Finding and discussion}

According to the coefficient of beta, T-value and P-value, the openness to experience and the extraversion variables have their influences towards the perceived ease of use and the self-efficacy, whereas the effect of perceived ease of use and the self-efficacy towards the perceived usefulness and the intention to use the internet are significant. The result revealed that there is a full mediation effect of the situational cognitive factor to the influence of the dispositional personality factor towards the intention to use the internet. This result is all along with the result founded by McElroy et al. (2007), Tuten and Bosnjak (2001) and Amiel and Sargent (2004), who noticed that the openness to experience character and the extraversion have a strong influence towards the situational cognitive factor and the intention to use the internet in general.

The same as the explanation before, the openness to experience is a character that keen to the abstract ideas, arts and artistic, tasting new gadgets, fond of adventures and having an excessive imagination. Those characteristics endorse human to use the internet as a media to search new ideas, creating imaginations and taking quest in the cyber world. Along with the control variable testing result, it is visible that age is negatively affected towards the intention to use the internet. It means that, the younger the age, the more they will accept and intent to use the internet compared to the older ones. This is concordance to the openness to experience character which we can found dominant in the younger age, particularly for the students in this research context. In the mean time, the other personality factors such as neuroticism, agreeableness, extraversion and conscientiousness do not influence the intention to use the internet.

Neuroticism is a negative character from a set of human characters. The neuroticism reflects the unstable characters, hothead, paranoid, anxiety and difficult to socialise with the others, which in the context of IT acceptability; the neuroticism character do not promote individual to use the internet. This result is concordance to the result founded by McElroy et al. (2007) and Amiel and Sargent (2004), who discovered that the neuroticism did not influence the intention to use the internet, especially for the needs of academic. On the contrary, with the neuroticism character someone is tends to use the internet to appease him without involving the others such as the online games. Based on them, the neuroticism character is not an intention to use the internet predictor for academic purpose.

The agreeableness is an open character to people opinions, respect and content in helping others, and really maintains the direct social interaction with the community. However, this character does not stimulate to use the internet especially if the user meets any obstacles in using the internet. Concordance to those of McElroy et al. (2007) and Landers and Lounsbury (2006) who discovered that agreeableness did not influence the intention in using the internet, this study has found the same outcome, where the agreeableness does not influence the intention to use the internet. Our result also showed that the agreeableness characteristics are tend to stay on the older age who are more keen to directly interact with other people, difficult to use the internet especially on the using of the internet for academic purpose. This indicated that the character is a potential source of resistance on accepting the internet technology, if the organisation does not afford to persuade and educate them better. On behalf of it, the institution is better to adapt the persuasion approach all along with a good education to invite this character to accept the internet technology through training programmes, and develop an online communication forum to constantly accommodate the importance of socialisation by this agreeableness character. 
Extraversion is a friendly character, receptive and likes to be within their social community. In the context of using the internet, this character tends to use the media for socialising and interacting with the cyber communities such as through chatting room and/or blog. Align with those of McElroy et al. (2007) and Amiel and Sargent (2004), they discovered that this character does not influence use of the internet in general, especially for academic purpose. On the other hand, this character will tend to use the internet for fun and social interaction. Based on the explanation above, to persuade this character to use the internet in the academic context, higher education institutions are expect to accommodate their needs without having to alter the main intention in using the internet on behalf of formal education purpose.

Conscientiousness type is a discipline character, detailed and retains to their plan on taking their actions. This character is ideal to students in terms of using the internet in academic environment as it is a strong predictor in the internet acceptability for academic purpose. The same with McElroy et al. (2007), this research has found the other extreme, where conscientiousness has no influence towards the intention to use the internet. This founding is contradictive to those characters which are intended to be relevant with the use of the internet in the context of academic purpose. The explanation that can be given about it is that, conscientiousness is not found in the students of FE Unib, where this reflected that the academic climate was not conducive enough for knowledge development. Therefore, on testing the hypotheses, this factor has no influence towards the intention to use the internet. This founding gave important information for higher education institution especially to FE Unib, that it need to renovate its academic climate so that it can be more conducive for knowledge development, that is through developing academic programmes which are more attractable to students for their academic purpose such as online journals.

The hypothesis testing for situational cognitive factor revealed that perceived usefulness has a positive influence towards the intention to use the internet. This founding is aligned with those of McElroy et al. (2007), which also found that perceived usefulness construct has a positive influence towards the intention to use the internet. It means that, the higher the confidence level of user about the benefits of using the internet, the higher will be their intention to use the internet. This is the same with the results shown by Davis (1989) and Davis et al. (1989), and many more post-researches which used the TAM model, where they stated that the perceived usefulness construct is the strongest predictor of all towards the intention to use IT.

Compeau and Higgins (1995) and Hsu and Chiu (2004) have found that self-efficacy is a predictor in using IT, especially the internet. Our research result showed that self-efficacy has a positive influence towards the intention to use the internet. It means that, the higher the confidence level about their ability to run certain activities through the internet which is based on their knowledge and skill concerning internet technology, the higher their intention to use the internet.

Based on the hypotheses testing of the three situational cognitive variables, the perceived ease of use variable did not give a direct positive influence towards the intention to use the internet. Our result is aligned with the research done by Davis (1989), where he also found that the perceived ease of use variable did not give a direct positive influence towards the intention, but it was an antecedent for the perceived ease of use which is also as a mediating variable to the influence of the perceived ease of use variable towards the intention to use the internet. The result of those three hypotheses 
testing of the situational cognitive variable indicated that the students' intention to use the internet within academic environment is affected by cognitive dimension (perception) on the use or benefits of IT, and the confidence level concerning their ability to use them.

Align with the result of magnitude comparative between dispositional personality factor and the situational cognitive revealed that the cognitive factor is more affective towards the intention to use the internet within academic environment compared to the personality factor. This result indicated that, in academic environment which is dominantly occupied by the rationality aspect (cognitive) in the social interactive process, the students' decision as IT user is more affected by the rationality factor on using the internet. Therefore, the character aspect which stays in each person gives less influence towards the intention to use the internet.

All those results above give an important information to higher education institution about investing and developing IS, where cognitive aspect (perception on advantages and confident upon the ability to use IT) is a strong predictor compared to the personality factor. Even though, individual characteristics (openness to experience) are still to be the predictor of internet acceptance. Thus, higher education institution should feel confident that the decision of investing on IT in form of internet is a right choice as long as the control system and the management on IS are done proficiently. The problem on the acceptance and the adoption of the internet are not actually the difficulties that inhibit the development of IS within higher education institutions as long as the perception and confidence that form on those IT is respectable in the eye of the system user.

In general, the result of this study contributes and affirms the discrepancy of theories as well as empirical behavioural IS research, where the dispositional personality and the situational cognitive factors are the predictor to identify the intention to use the internet in the higher education institution. However, the cognitive factor is the main predictor compared to the personality factor which by then can be concluded that this research model sustain many other behavioural IS researches which apply the perceptual cognitive dimensions such as the TAM, TPB and UTAUT, where all of them showed the constructs as to be the main predictor in accepting the perceptual based on IT (Robey, 1983). By considering all the factors above, further research then is hope to be more focused in exploring the situational personality and the dispositional cognitive factors which are erratically studied in terms of empirical research.

\section{Conclusion}

This research is aimed to test the mediation effect of the situational cognitive factors on the influence of the dispositional personality factors towards intention to use the internet. The motivation of the writer to test is because of the lag being in theories and many empirical researches on IT acceptance which use the two factors above. This study is different from the prior researches in terms of the dispositional personality model of measure which employed the IPIP model, and the situational cognitive factors which used the perceived ease of use construct, the perceived usefulness construct and the self-efficacy.

The research design applied is the descriptive-confirmatory research with survey approach. The primary data are taken cross-sectional from 350 respondents which all of them are the students who use the internet in FE Unib. The sampling procedure is conducted by using the non-probability with convenience sampling technique. 
The result indicated that there is a full mediation effect of the situational cognitive factors on the influence of the dispositional personality factors towards the intention to use the internet. However, only the openness to experience and the extraversion variables on the dispositional personality factors that significantly affect the situational cognitive factors while all the situational cognitive variables have a significant influence towards the intention to use the internet.

The result of this research gives important contributions to higher education institutions which are developing their IT. It indicated that on the higher education environment, the prediction of the internet technology acceptant is more dominantly mediated by the situational cognitive factors rather than the direct prediction of the dispositional personality factors. This affirms that theoretically the situational cognitive constructs are standards and better in describing the IT phenomena compared to the prediction of the dispositional personality construct which are dominantly by people with the openness to experience character such as those who keen for experience, knowledge, new ideas and challenges. Despite of it, people will accept and adopt the internet if they think that the internet can give benefits to them such as increasing the performance, productivity as well as speeding up works and system user may possess conviction upon their ability in using the internet. Yet, in general, individual character is not a strong predictor in using IT, but the perceptual cognitive aspect is more influential towards the intention to use the internet.

\section{Limitation}

This study has some weaknesses, sort of this study only explore one type of Information Technology (IT) which is the internet, thus the result cannot be generalised for the use of other IT. The subject of the study is restricted only to the IT user within the higher education institution which in this case is the academic environment; therefore the result is difficult to generalise for other subjects of research. This study only measures the level of intention which based on the perceptual, not to the actual using. Therefore, the consideration is based on the subjective parameter of respondent's opinion. There are too many question items to measure the personality construct which made respondents unserious or weary in filling the questionnaires. The effect from this condition induced many indicators from the personality construct to be invalid.

\section{Suggestion}

The suggestions that can be presented in this research are: the same research model can be use to measure the acceptant and the adoption of IT beside the web-based internet, such as the IT-based cellular communication technology. It is better to enlarge the research sample, not only to the higher education environment, but also for the other type of IT user such as the e-commerce agents. The scope of the measurement can be developed with the measuring of the actual using of the internet, so that there is a comparison between the subjective respondent perception and the objective parameter. If the next research use the dispositional personality constructs, therefore it is better to strictly control the respondents when collecting data as to avoid response bias, such as closely assist the respondent when filling the self-administered questionnaire, or by giving rewards or presents to stimulate the respondent to fill the questionnaire better. 


\section{References}

Ackoff, R.L. (1960) 'Unsuccessful case studies and why', Operations Research, Vol. 2, No. 8, pp.259-263.

Agarwal, R. and Karahanna, E. (2000) 'Time flies when you are having fun: cognitive absorption and beliefs about information technology usage', MIS Quarterly, Vol. 24, pp.418-430.

Amiel, T. and Sargent, S.L. (2004) 'Individual differences in internet usage motives', Computers in Human Behavior, Vol. 20, No. 6, pp.711-726.

Bandura, A. (1982) 'Self-efficacy mechanism in human agency', American Psychologist, Vol. 2, No. 37, pp.122-147.

Barnett, T., Kellermanns, F.W., Pearson, A.W. and Pearson, R.A. (2007) 'Measuring information system usage: replication and extensions', Journal of Computer Information Systems, Winter.

Buchanan, T., Jhonson, J.A. and Goldberg, L.R. (2005) 'Implementing a five-factor personality inventory for use on the internet', European Journal of Psychology Assessment, Vol. 22, No. 2, pp.115-127.

Burkhat, M.E. and Brass, D.J. (1990) 'Changing patterns or patterns of change: the effects of a structure and power', Administrative Science Quarterly, Vol. 35, pp.104-127.

Chesney, T. (2006) 'An acceptance model for useful and fun information systems', An Interdisciplinary Journal on Humans in ICT Environments, Vol. 2, No. 2, pp.225-235.

Chin, W.W. (1995) 'Partial least square is to LISREL as principal components analysis is to common factor analysis', Technology Studies, Vol. 2, pp.315-319.

Compeau, D.R. and Higgins, C.A. (1995) 'Computer self-efficacy: development of a measure and initial test', MIS Quarterly, Vol. 19, No. 2, pp.189-211.

Davis, F.D. (1989) 'Perceived usefulness, perceived ease of use and end user acceptance of information technology', MIS Quarterly, Vol. 13, No. 3, pp.319-340.

Davis, F.D., Bagozzi, R.P. and Warhsaw, P.R. (1989) 'User acceptance of computer technology: a comparison of two theoretical models', Management Science, Vol. 35, No. 8, pp.982-1003.

Goldberg, L.R. (1990) 'An alternative "description of personality": the big-five factor structure', Journal of Personality and Social Psychology, Vol. 59, pp.1216-1229.

Hair Jr., J.F., Black, W.C., Babin, B.J., Anderson, R.E. and Tatham, R.L. (2006) Multivariate Data Analysis, 6th ed., Pearson Prentice Hall, NJ.

Hartono, J.M. (2007a) Sistem Informasi Keperilakuan, Edisi I, Andi Offset, Yogyakarta.

Hill, T., Smith, N.D. and Mann, M.F. (1987) 'Role of efficacy expectations in predicting the decision to use advanced technologies: the case of computers', Journal of Applied Psychology, Vol. 2, No. 72, pp.307-313.

Hollenbeck, J.R. and Brief, A.P. (1987) 'The effects of individual differences and goal origins on goal setting and performance', Organisational Behavior and Human Decision Performance, Vol. 3, No. 40, pp.392-414.

Hsu, M.H. and Chiu, C.M. (2004) 'Predicting electronic service continuance with a decompensated theory of planned behavior', Behavior and Information Technology, Vol. 23, No. 5, pp.359-373.

Igbaria, M., Parasuraman, S. And Baroudy, J.J. (1996) 'A motivational model of microcomputer usage', Journal of Management Information System, Vol. 13, pp.127-143.

Kim, H-W., Chan, H.C. and Chan., Y.P. (2007) 'A balanced thinking-feelings model of information systems continuance', International Journal of Human-Computer Studies, Vol. 65, pp.511-525.

Landers, R.N. and Lounsbury, J.W. (2006) 'An investigation of big five and narrow personality traits in relation to internet usage', Computers in Human Behavior, Vol. 22, No. 2, pp.283-293. 
Lu, J., Liu, C., Yu, C. and Yao, J.E. (2007) 'Exploring factors associated with wireless internet via mobile technology acceptance in mainland China', Communications of the International Information Management Association, Vol. 3, No. 1.

McElroy, J.C., Hendrickson, A.R., Townsend, A.M. and DeMarie, S.M. (2007) 'Dispositional factors in internet use: personality versus cognitive style', MIS Quarterly, Vol. 31, No. 4, pp.809-820.

Ndubisi, N.O. (2005) 'Effect of perception and personal traits on computer technology adoption by women entrepreneurs in Malaysia', Journal of Asia Entrepreneurship and Sustainability.

Robey, D. (1983) 'Cognitive style and DSS design: a comment on Huber's paper', Management Science, Vol. 29, No. 2, pp.580-582.

Tenenhaus, M., Vinzi, V.E., Chatelin, Y.M. and Lauro, C. (2005) 'PLS path modelling', Computational Statistics and Data Analysis, Vol. 48, pp.159-205.

Thatcher, J.B., Misty, L.L., Jaejoo, L. and McKninght, D.H. (2007) 'Internet anxiety: an empirical study of the effects of Kepribadian, beliefs and social support', Information Management, Vol. 44, pp.353-363.

Tuten, T. and Bosnjak, M. (2001) 'Understanding differences in web usage: the role of need for cognition and the five factor model of personality', Social Behavior and Personality, Vol. 29, No. 4, pp.391-398.

Venkantesh, V. (2000) 'Determinants of perceived ease of use: integrating control, intrinsic motivation and emotion into the technology acceptance model', Information System Research, Vol. 11, No. 4, pp.342-365.

Venkatesh, V., Morris, M.G., Davis, G.B. and Davis, F.D. (2003) 'User acceptance of information technology: toward unified view', MIS Quarterly, Vol. 27, No. 3, pp.425-478.

Webster, J. and Martocchio, J.J. (1992) 'Microcomputer playfulness: development of a measure with workplace implications', MIS Quartely, Vol. 2, No. 16, pp.201-226.

Webster, J. And Martocchio, J.J. (1993) 'Turning work into play: implication for microcomputer software training', Journal of Management, Vol. 19, pp.127-146.

Yi, Y., Wu, Z. and Tung, T.T. (2006) 'How individual differences influence technology usage behavior? Toward an integrated framework', Journal of Computer Information Systems, Winter.

Zmud, R.W. (1979) 'Individual differences and MIS success: a review of the empirical literature', Management Science, Vol. 25, No. 10, pp.966-979. 